\title{
Divergências entre a construção passiva no português brasileiro e no inglês: evidências de corpus oral
}

\author{
Mara P. Guimarães* \\ Ricardo A. de Souza**
}

\begin{abstract}
Resumo
A visão transformacional na construção passiva não esgota todas as suas possibilidades. Neste estudo, propomos uma visão construcional da construção, na qual ela é tomada como entidade teórica independente. Apesar de sintaticamente congruente no português brasileiro (PB) e no inglês, esta construção não pode ser tomada como equivalente uma vez que o PB apresenta uma opcionalidade para alcance de efeitos semântico-pragmáticos que são obtidos no inglês apenas através da construção passiva. Considerando-a como construção dentro da Gramática de Construções (GOLDBERG, 1995; 2006), foi feita uma análise de frequência da construção em corpora de fala do português brasileiro e do inglês, na qual foi atestada uma diferença distribucional. Conjectura-se, então, que a passiva recupere representações construcionais distintas no PB e no inglês.
\end{abstract}

Palavras-chave: Construção Passiva. Gramática de Construções. Análise de Corpora.

\section{Introdução}

A construção passiva no português brasileiro (doravante PB) e no inglês já foi objeto de análise sob diferentes perspectivas: análise de corpora (DUARTE, 1990), aquisição (GABRIEL, 2003), diacronia (CYRINO, 2007), entre vários outros. Este estudo oferece como acréscimo à literatura a hipótese da diferença representacional da construção neste par linguístico.

Argumentamos aqui que a existência da passiva no $\mathrm{PB}$ e no inglês não é suficiente para presumir que as construções sejam equivalentes. O PB dispõe 
de alternativas para as funções de retirada do agente e de promoção de objeto a tópico, enquanto no inglês estes efeitos semântico-pragmáticos são obtidos apenas pela construção passiva. Essa opcionalidade sugere que existam propriedades distribucionais distintivas a respeito desta construção nas duas línguas. De fato, Duarte (1990) observa uma discrepância distribucional entre as construções passivas no PB e no inglês em uma análise de corpus escrito. Segundo a autora, para cada construção passiva encontrada no corpus do inglês, foram encontradas sete construções ativas. Já no $\mathrm{PB}$, a relação foi de uma construção passiva para cada vinte construções ativas. Em números absolutos, o número de passivas encontradas no inglês foi mais do que duas vezes maior do que no PB.

Propomos ainda a análise desta construção sob a perspectiva da Gramática de Construções (GOLDBERG, 1995; 2006). A visão não transformacional da passiva atribui a ela o status de entidade teórica independente, e, como tal, passível de recuperar representações distintas daquelas que recuperam construções ativas (consideradas correspondentes sob a perspectiva transformacional) e construções passivas em outras línguas que não o PB. Baseamo-nos em um estudo de corpora de fala para investigar diferenças de produtividade que oferecem suporte à hipótese de que há uma diferença representacional a despeito da congruência sintática.

Essa divergência entre o $\mathrm{PB}$ e o inglês não se restringe à construção passiva. A configuração sintática (SN, SV, SN, SAdj) é um exemplo de estrutura possível no $\mathrm{PB}$, mas cuja representação construcional não coincide com aquela do inglês (OLIVEIRA; SOUZA, 2012):

1. John stabbed the man dead.

2. John esfaqueou o homem morto.

A expressão formal ilustrada em (1) é pareada a uma construção resultativa adjetiva no inglês, em que a mudança de estado sofrida pelo SN objeto é expressa pelo SAdj: "o homem", portanto, morreu como resultado da ação de "esfaquear". No PB, a leitura resultativa é barrada: na sentença (2), o SAdj é uma descrição do SN objeto (predicativo do objeto na gramática tradicional).

A seção 1 a seguir define a construção passiva analisada neste estudo. As seções 2 e 3 se dedicam à descrição da construção sob as perspectivas transformacional e construcional, respectivamente. A seção 4 apresenta as alternativas à passiva presentes no PB. Na seção 5, o estudo de corpora de fala é descrito, e são oferecidas as considerações finais na seção 6 . 


\title{
1. A construção passiva no PB e no inglês
}

Hawad (2004) oferece uma definição compreensiva da passiva dentro da gramática tradicional, considerada satisfatória para a delimitação do objeto deste estudo:

\begin{abstract}
A voz passiva propriamente dita, denominada "analítica" tradicionalmente, caracteriza-se, em nível sintático-semântico, por ter o paciente da ação verbal na função de sujeito e, em nível morfossintático, por construir-se como uma locução verbal formada pelo particípio do verbo principal e, tipicamente, pelo verbo auxiliar "ser". (HAWAD, 2004, p.23).
\end{abstract}

A gramática tradicional (doravante, GT) pressupõe uma reversibilidade entre as construções ativa e passiva para verbos transitivos: se o verbo seleciona um objeto não preposicionado, ele pode necessariamente ocorrer na construção passiva; consequentemente, todos os verbos que ocorrem na construção passiva podem ser encontrados na construção ativa (HAWAD, 2004). Embora tenhamos adotado esse conceito de reversibilidade para restringir os verbos observados neste estudo, não compartilhamos da perspectiva lexicalista de teorias derivacionais da sintaxe nas quais o verbo, e não a construção, seleciona a estrutura argumental. A propriedade de reversibilidade pode ser observada nas sentenças (3) e (4), apresentando o verbo "lavar":

3. O funcionário está lavando o carro.

4. O carro está sendo lavado.

A construção correspondente à passiva analítica no inglês é denominada por Levin (1993) "passiva verbal"', e, de maneira semelhante à passiva descrita na GT, apresenta verbo auxiliar be (correspondente ao "ser" da passiva no $\mathrm{PB}$ ) seguido pela forma participial do verbo principal, assim como permite a reversibilidade entre ativa e passiva (exemplos retirados de LEVIN, 1993, p. 86) ${ }^{2}$ :

5. The cook sliced the mushrooms.

O cozinheiro fatiou os cogumelos.

6. The mushrooms were sliced by the cook.

Os cogumelos foram fatiados pelo cozinheiro.

1 Neste artigo, nos referiremos tanto à "passiva analítica" da GT quanto à "passiva verbal" descrita por Levin (1993) somente como "passivas".

2 Todos os exemplos em inglês serão seguidos de suas traduções literais no PB. 
O inglês permite a passivização de estruturas apresentando objeto precedido por preposição quando esta é idiomaticamente selecionada pelo verbo, i.e., quando uma alteração na preposição implica em mudança no significado ou até mesmo agramaticalidade da sentença:

7. The employees took advantage of the lack supervision.

Os funcionários tiraram proveito da supervisão descuidada.

8. The lax supervision was taken advantage of.

A supervisão descuidada foi tirada proveito de.

Existe no inglês ainda a possibilidade de passivizar verbos inergativos cujo adjunto é preposicionado, desde que apresentem sujeito animado: são as chamadas "passivas preposicionais" (LEVIN, 1993; 86), ou "passivas preposicionais de adjunto" (TSENG, 2007). Os exemplos abaixo foram retirados de Davison (1980, p. 43):

9. John sat on this chair.

John sentou nesta cadeira.

10. This chair was sat on by John.

11. Esta cadeira foi sentada em por John.

De forma a possibilitar a comparação direta entre o PB e o inglês, as construções passivas analisadas neste estudo atendem às mesmas exigências:

(I) têm as funções de suprimir o agente da proposição e de topicalizar o objeto;

(II) são formadas pelo verbo auxiliar ser/be seguidas pela forma participial do verbo principal;

(III) apresentam a propriedade da reversibilidade entre as construções ativa e passiva;

(IV) permitem a indicação do agente da passiva em caso oblíquo, sem alteração da proposição original (GIVÓN, 1990).

Esses parâmetros são essenciais na identificação de construções passivas no inglês, língua em que a restrição da configuração sintática não é em si suficiente: o verbo de ligação em questão, to be, pode ser mapeado no PB como "ser" e como "estar". No PB, essas duas entradas lexicais disponíveis permitem distinguir entre o sentido dinâmico e estativo de uma proposição mais objetivamente do que no inglês. Logo, construções do PB apresentando o verbo "ser" seguido de particípio, como em (11), foram consideradas construções passivas, enquanto construções apresentando o verbo "estar" seguido de particípio, como em (12), foram consideradas construções descritivas":

3 As sentenças (11) e (12) são versões curtas de ocorrências do C-Oral-Brasil I (RASO; MELLO, 
12. O papel foi inventado na China.

13. Tio Carlos estava instalado aqui em Belo Horizonte.

O critério de categorização das sentenças do inglês como construções passivas, foi, além da sua configuração sintática, o seu correspondente no PB. Tomemos como exemplo a sentença (13), apresentando o verbo retire (aposentar-se) ${ }^{4}$ :

14. The horse was retired from stud duty.

O cavalo foi aposentado das funções de garanhão.

A sentença (13) é considerada um exemplo de construção passiva, pois atende aos critérios (i)-(iv) estabelecidos na introdução desta seção. Note que a adição do sintagma preposicional agente, ilustrada em (14), mantém o sentido original da sentença:

16. The horse was retired from stud duty by the trainer.

O cavalo foi aposentado das funções de garanhão pelo treinador.

Contudo, sentenças do inglês apresentando a configuração sintática desejada, mas cuja forma correspondente no PB pode apresentar tanto o verbo "ser" quanto o verbo "estar" sem que haja alteração do sentido descritivo da proposição, não entraram nas análises deste estudo:

16. These horses are retired.

Estes cavalos estão aposentados.

Estes cavalos são aposentados.

É importante observar que a possibilidade de utilização tanto do "ser" quanto do "estar" na sentença correspondente a (15) no PB não gera ambiguidade acerca de seu status como sentença descritiva. A diferença de sentido entre os verbos de ligação é apenas a de estado temporário ou permanente, e retired mantém a função de complemento nominal das duas formas. Construções passivas não apresentam essa opcionalidade. Substituindo-se o verbo de ligação da sentença (11), por exemplo, temos a improvável sentença (16):

17. ? O papel estava/esteve inventado na China.

É possível notar ainda que a adição do sintagma preposicional agente na sentença (15), reproduzida na sentença (17) abaixo, resulta em uma construção que não satisfaz as condições de felicidade em inglês ou no PB:

18. ? These horses are retired by the trainer.

? Estes cavalos estão aposentados pelo treinador.

? Estes cavalos são aposentados pelo treinador. 


\section{A construção passiva em perspectivas transformacionais e derivacionais}

Goldberg (2006) assinala que ao longo da história da teorização gramatical produzida dentro do modelo gerativista, a heurística derivacional (incialmente referida como transformacional) tem um papel central. Tal como explicitado pela autora (op cit., p. 19), tal heurística baseia-se na análise de uma dada estrutura sintática em relação a outra estrutura que, de certo modo, a parafraseia.

A abordagem das orações passivas na teoria da gramática gerativa pode ser tomada como um exemplo da transição que a noção de construção teve ao longo da história dessa teoria. Tal como descrito em van Riemsdijk; Williams (1986), em sua fase inicial, a teoria buscava estipular os mecanismos transformacionais a partir dos quais se derivavam construções sintáticas específicas, buscando-se concomitantemente máxima abrangência descritiva. A partir da década de 1970, contudo, a teoria gerativa passa a ter como meta principal a elaboração de um modelo geral da faculdade humana da linguagem, mais que o objetivo de descrever exaustivamente o inventário de padrões frasais de línguas específicas. Nessa mudança de foco epistemológico, ganha força entre os linguistas cujo trabalho se orienta por esse quadro teórico a formulação de mecanismos gramaticais mais gerais, em detrimento da descrição de construções, noção que deixa de ter relevância teórica para a gramática gerativa.

Segundo van Riemsdijk; Williams (1986), a abordagem transformacional das orações passivas postulava duas operações de movimento específicas, uma de pré-posicionamento de sintagmas nominais (NP-preposing) e outra de pósposicionamento do mesmo tipo de sintagma (NP-postposing). Tal tratamento é claramente capaz de lidar com construções que os autores denominam "passivas canônicas", tanto em sua expressão em língua portuguesa quanto em sua expressão em língua inglesa.

Na passiva analítica, a relação de simetria semântica, do ponto de vista da proposição básica, entre a oração na voz ativa e a oração na passiva que é convidativa à compreensão de que a oração passiva é derivada diretamente de uma oração ativa com verbo transitivo. Esta é tipicamente a análise da construção passiva descrita em gramáticas tradicionais. As transformações acima descritas se aplicam prontamente à passiva canônica, ou seja, é aceitável descrever a passiva como resultante da operação de movimento do sintagma nominal que realiza o sujeito da ativa para a posição de objeto de preposição pós-verbo, e do sintagma 
nominal que realiza o objeto direto do verbo lexical na oração ativa para a posição pré-verbal de sujeito da passiva ${ }^{5}$.

No fim da década de 70, surge a hipótese da inacusatividade, que trata de diferenças semânticas e especificidades do comportamento sintático dos verbos intransitivos (CHIERCHIA, 2004). Segundo essa hipótese, verbos monoargumentais dividem-se em verbos cujo único argumento é gerado sintaticamente em posição externa ao sintagma verbal (ex.: A menina correu), e em verbos cujo único argumento é gerado em posição de objeto, ou seja, de complemento de núcleos verbais (ex. A menina chegou). Segundo esta hipótese, os verbos inacusativos não licenciam a atribuição de caso acusativo aos sintagmas nominais gerados na posição de objeto, forçando-os a mover-se para uma posição licenciadora de atribuição de caso, tipicamente a posição do sujeito oracional, onde a flexão finita licencia a atribuição de caso nominativo.

A hipótese da inacusatividade fomentou, na teoria gerativa, uma interpretação derivacional da passiva que não a toma como transformação direta de uma oração ativa correlata. Segundo Chierchia (2004), em tal interpretação, a construção passiva é compreendida como sustentada por uma caracterização morfológica de verbos lexicais que, no caso do PB, é constituída pela anteposição do verbo ser como morfema livre e forma participial de passado, por afixação junto à raiz lexical. A morfologia passiva, nesta interpretação, leva à inacusativização do verbo lexical. Como núcleo verbal inacusativo, verbos em morfologia passiva não realizariam atribuição de caso requerido apara o licenciamento dos sintagmas nominais que os complementam, levando-os assim à derivação por movimento que resulta em tais sintagmas nominais ocuparem a posição onde são licenciados com caso nominativo. A figura 1 abaixo ilustra parcialmente a estrutura da qual a oração passiva $O$ decreto foi assinado seria derivada, segundo esta interpretação da construção passiva.

5 Tal como apontado por van Riemsdijk; Williams (1986), desde muito cedo na teorização gerativista se observa que na língua inglesa ocorrem passivas nas quais o sujeito seria objeto indireto em uma oração ativa correlata. Esse fato linguístico é apontado pelos autores como uma das questões empíricas que motivaram a substituição do modelo transformacional por um modelo derivacional mais abstrato, na direção da teoria de princípios e parâmetros, na qual desenvolveu-se uma teoria geral de movimento de constituintes incialmente denominada "mover $\alpha$ ". 
FIGURA 1: Derivação de "O decreto foi assinado".

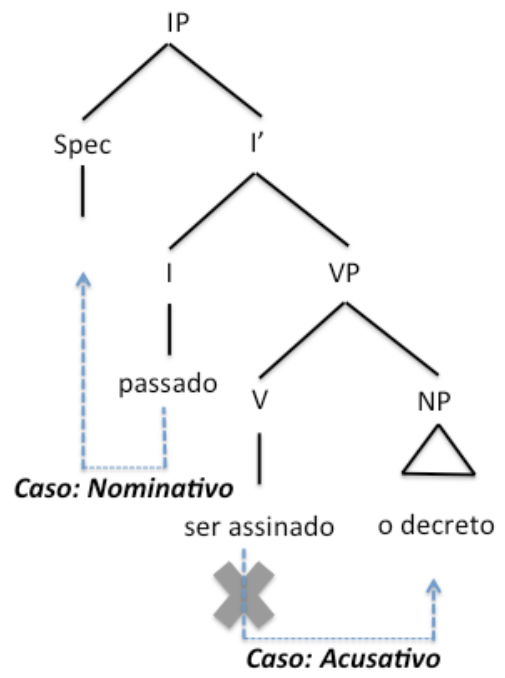

Fonte: Baseado em Haegeman; Guéron (1999) e Chierchia (2004).

A interpretação da construção passiva como inacusativização de verbos lexicais por morfologia passiva não esgota o fenômeno na língua inglesa, contudo. As passivas preposicionais são um caso no qual, se a relação com uma sentença ativa equivalente fosse tentada, o sintagma nominal realizado como sujeito seria encontrado na posição de adjunto, não de potencial objeto direto. Este caso é ilustrado no par de sentenças (9) e (10), reproduzidas em (18) e (19).

19. John sat on this chair.

John sentou nesta cadeira.

20. This chair was sat on by John.

Esta cadeira foi sentada em por John.

Nota-se na sentença 18 acima que o sintagma nominal this chair é marcado por caso designado pela preposição on. Nota-se, além disso, que o verbo lexical sit não é um verbo inacusativo. Assim, trata-se de um caso aparentemente opaco a tratamentos teóricos que buscam abordá-lo por mecanismos transformacionais ou derivacionais globais. Tseng (2007) aponta a dificuldade que passivas 
preposicionais representam para a teoria lexicalista:

Por princípio, adjuntos não são selecionados pelo verbo e não são visíveis em sua descrição lexical. Seria impossível, num primeiro momento, derivar uma entrada lexical para o verbo no particípio partindo de seu verbo intransitivo, já que o sujeito da passiva é originado em um SP modificador inacessível. (TSENG, 2007, p. 279).

Pautando-se nos problemas da construção passiva na língua inglesa, van Riemsdijk; Williams (1986, p. 111) argumentam que o termo passiva é um guardachuva para diversos casos díspares.

Entendemos que a hipótese de que a construção passiva é somente aparentemente correlata a sentenças ativas com verbos transitivos justifica a hipótese de que se trata de uma construção autônoma, ou seja, não derivada, na representação linguística de uma dada língua. Tal hipótese assenta-se em uma conceptualização de construção como uma entidade teórica para a análise linguística. Sobretudo, ela nos conduz à previsão de que não há necessariamente correspondência plena entre as construções passivas que tem aparentemente estruturas idênticas, mas que ocorrem em línguas diferentes, como é o caso do português e do inglês. Na seção seguinte, abordamos a noção teórica de construção que emerge do quadro conceitual denominado gramática de construções, para em seguida descrevermos o estudo no qual exploramos a previsão empírica de nossa hipótese.

\section{A passiva como construção dentro da Gramática de Construções}

Em uma visão mais formalista da sintaxe, a estrutura argumental é a propriedade do verbo de determinar o número de $\mathrm{SNs}$ e outros constituintes necessários em uma construção gramatical (JUFFS, 2000). Essa concepção implica que a estrutura argumental está codificada no item lexical (GRIMSHAW, 1992 apud SOUZA; MELLO, 2007), fazendo com que instâncias de variação translinguística sejam atribuídas às idiossincrasias da língua em questão. $\mathrm{O}$ verbo do inglês run, por exemplo, aceita a alternância do movimento induzido, ao contrário do verbo "correr" no PB:

21. The researchers ran the mouse through the maze.

22. *Os pesquisadores correram o rato pelo labirinto. 
A agramaticalidade de (21) no PB decorreria então das propriedades semânticas do verbo: "correr" não apresenta possibilidade de controle externo, como é o caso do verbo correspondente run, do inglês e, portanto, não aceita causativização (CAMBRUSSI, 2009). Dentro da proposta da Gramática das Construções (GOLDBERG, 1995), a estrutura sintática presente em (20) e (21) é uma construção resultante do pareamento da estrutura semântica X CAUSE Y TO MOVE TO Z com a expressão formal correspondente (SN, SV, SN, SP).

Goldberg (1995) critica a atribuição de idiossincrasias somente ao item lexical, e argumenta que uma abordagem bottom-up (lexicalista) da estrutura argumental não dá conta dos fenômenos observados no inglês (op cit., p. 1). Estruturas levemente distintas apresentando os mesmos itens lexicais, por exemplo, apresentam diferenças de significado e licenciamento. Dentre as sentenças (22)-(24) abaixo, apenas a sentença (22) consegue transmitir a mensagem de que uma pessoa descobriu que a outra era mexicana após olhar alguns arquivos ${ }^{6}$ :

23. When I looked in the files, I found that she was Mexican.

Quando eu olhei os arquivos, eu descobri que ela era mexicana.

24. ? When I looked in the files I found her to be Mexican.

Quando eu olhei os arquivos eu a descobri ser mexicana.

25. *When I looked in the files I found her Mexican.

Quando eu olhei os arquivos eu a descobri mexicana.

A infelicidade de (23) e a impossibilidade de (24) não podem ser explicadas apenas pelo verbo, uma vez que (22) apresenta os mesmos itens lexicais e atende aos critérios de felicidade e gramaticalidade da língua inglesa. As diferenças são resultantes das restrições das construções sobre os itens lexicais - e não o inverso.

Toma-se construções, portanto, como entidades teóricas autônomas, independentemente representadas na mente do falante e cujo significado não depende dos itens lexicais que nela ocorrem (GOLDBERG, 1995; ELLIS, 2003). Construções mostram efeitos de protótipos: o sentido global da proposição é alcançado através da combinação das propriedades semânticas do verbo com o sentido central da construção. Uma vez que cada construção de oração simples codifica um evento básico à experiência humana, os fatores de licenciamento de uma construção não se restringem a padrões distribucionais de categorias morfológicas, mas sim ao caráter cíclico da semântica e da sintaxe: é a construção, e não o verbo, que tem o poder de seleção argumental (BOLINGER, 1968, apud GOLDBERG, 1995, p. 3).

6 Exemplos de Borkin (1974) apud Goldberg (1995, p. 3). 
A colocação da construção como entidade independente implica a rejeição da existência de formas subjacentes ou de estruturas profundas, resultando em um modelo não transformacional no qual construções não canônicas não são simples variações de construções canônicas. Isso significa que a construção passiva não pode ser considerada uma construção derivada da construção ativa. Entretanto, Goldberg (1995) aponta que construções de orações complexas, como a construção passiva, não codificam cenas básicas da experiência humana, mas apenas oferecem alternativas à estrutura informacional da oração. Diferentemente das construções de orações simples, as construções de orações complexas se relacionam ao conhecimento pragmático que pode, por exemplo, exigir a topicalização ou focalização de determinado argumento em dado contexto linguístico. Ellis (2003) aponta que a forma como estruturamos sentenças é reflexo de nossa percepção e categorização do mundo real:

Os diferentes graus de saliência ou proeminência dos elementos envolvidos nas situações que desejamos descrever afetam a seleção do sujeito, objeto, adverbiais e outros elementos da sentença (...). Na produção, o que expressamos reflete quais partes do evento atraem nossa atenção (...). Na compreensão, construções linguísticas abstratas (como locativos, dativos e passivas) servem como uma "lente de aumento" para o ouvinte, guiando a sua atenção para uma perspectiva particular da cena, ao mesmo tempo que coloca outros aspectos no fundo. (ELLIS, 2003, p. 65).

Além de especificar propriedades de uma expressão definindo sua forma semântica, sintática e morfológica, a construção também especifica as funções semânticas, pragmáticas e/ou do discurso associadas a ela. A assimetria observada na aceitação da causativização ilustrada em (20) e (21) é atribuída diretamente às construções: a construção que indica a indução externa do movimento no PB não está associada a uma estrutura formal apresentando causativização sintética, e sim a uma estrutura com ocorrência de verbo causativo explícito, como (25):

26. Os pesquisadores fizeram o rato correr pelo labirinto.

A construção passiva é então definida como uma estrutura complexa que não reflete uma experiência básica, mas sim uma necessidade pragmática do falante de reconfigurar a estrutura informacional da expressão. No PB, as funções pragmáticas principais exercidas pela passiva são a de retirada do agente proposicional e topicalização do objeto, embora existam alternativas para a obtenção de tais efeitos. Estas alternativas estão descritas na seção 4 a seguir. 


\section{Alternativas do PB}

\subsection{A partícula se}

A partícula se do PB é encontrada em construções reflexivas (26) e recíprocas (27), e exercem ainda a função de atribuir um caráter dramático à ação (28) (SAID ALI, 2008):

27. Pedro matou-se.

28. Eles odeiam-se.

29. O homem foi-se.

A partícula é também um mecanismo de retirada do agente da proposição (SAID ALI, 2008; HAWAD, 2004). Não obstante a função específica, a natureza da estrutura apresentando o se é motivo de debate. Em sentenças como (30), a partícula se pode ser considerada partícula apassivadora (se indefinido) ou índice de indeterminação do sujeito (se impessoal), embora a literatura ofereça evidências em favor da segunda opção (SAID ALI, 2008; CYRINO, 2007):

30. Vende-se pão.

Aforma da construção passiva observada em(30)é tradicionalmente denominada "passiva sintética", e é construída a partir da afixação do clítico se a um verbo que aceita complemento não preposicionado. Em termos de sua funcionalidade em relação à estrutura informacional do texto, tanto a passiva sintética aqui descrita quanto a passiva analítica (definida na seção 2) são mecanismos de expressão de um Processo sem a especificação do Agente. Entretanto, na forma não marcada, apenas a passiva analítica permite a tematização do Objeto, enquanto a passiva sintética tematiza o Processo. Embora a tematização do Objeto seja a motivação principal para a escolha da forma analítica, a tematização do Processo não é fator relevante para a escolha da forma sintética (HAWAD, 2004, p. 106; 117).

Vale ressaltar que a passiva sintética e a passiva analítica não são completamente intercambiáveis. A sentença (30) poderia facilmente ocorrer na forma analítica ilustrada em (31), enquanto a alternância de (32) resulta na sentença agramatical (33):

31. Pão é vendido.

32. Vai-se muito à igreja.

33. *À igreja é ido muito.

A estrutura da passiva sintética no PB é, na verdade, classificada como construção ativa sem sujeito na análise diacrônica de Said Ali (2008): "Pelo 
histórico que fizemos do [se] medial, a dúvida deixa de subsistir. Consideramos o reflexivo se como elemento formativo do medial analítico; não o destacamos do verbo; temos uma oração sem sujeito gramatical" (op cit., p. 106). O argumento parte do princípio de que o verbo em primeira posição na oração pode ser substituído por um número infinito de outros verbos, assim como o substantivo que se segue. O único elemento constante é "a pessoa inominada, a incógnita real ou fingida, de quem a ação necessariamente dimana" (op.cit., p. 107-108).

Cyrino (2007), por outro lado, se baseia na ausência de concordância entre o verbo e seu argumento interno, observada em análise diacrônica de corpora, para afirmar que as estruturas com o se como partícula apassivadora não ocorrem no PB desde o final do século XIX: "o se passivo, que detona a concordância do verbo com o DP argumento interno, desapareceu completamente" (op cit., p. 90). A substituição do SN em (30) por outro SN com traço de plural (34) não modifica a morfologia do verbo e mantém o sentido da proposição. Ademais, a partícula se não permite a indicação do agente com SP (34):

34. Vende-se cenouras.

35. ? Vende-se cenouras pelo Pedro. ${ }^{7}$

Logo, com base nos estudos de Said Ali (2008) e Cyrino (2007), não categorizamos estruturas apresentando a partícula se como construções passivas, mas sim como mecanismos de supressão do agente e topicalização do objeto concorrentes à passiva. Já no inglês, sentenças com sujeito indeterminado também são sentenças ativas. Sendo esta uma língua não pro-drop, a indeterminação do sujeito pode ser indicada pelo uso do pronome pessoal de terceira pessoa do plural they:

36. They are fixing the road.

Eles estão consertando a estrada.

\subsection{Construções com promoção do argumento}

Uma segunda alternativa ao uso da passiva para supressão do agente e topicalização do objeto são as construções com promoção do argumento. A sentença (36), na qual o argumento interno do verbo ocorre em posição de sujeito, é equivalente à sentença (37) na passiva (exemplos de CYRINO, 2007). Entretanto,

7 A leitura não pretendida da sentença (34) é a de que um agente, ainda indefinido, realiza a ação de vender cenouras no lugar do Pedro. 
esta estrutura não é licenciada no inglês, como observado em (38):

37. A revista está xerocando.

38. A revista está sendo xerocada.

39. *The magazine is copying.

Apesar de não haver indicação do agente em nenhuma das duas estruturas, não é possível dizer que houve em (36) uma supressão do agente uma vez que este tipo de construção não projeta um argumento externo. Essa característica pode ser observada a partir da adição de um adjunto expressando intenção, que resulta em uma sentença sem sentido (39). Note que a mesma adição na construção passiva não apresenta problemas (40):

40. ? A revista está xerocando para ganhar tempo.

41. A revista está sendo xerocada para ganhar tempo.

A sentença (39) perde o sentido porque o sujeito de "para ganhar tempo" seria o agente implícito da ação de "xerocar". A configuração sintática de uma construção com promoção de argumento é idêntica à de uma construção ativa. É previsível, então, que a construção aceite apenas sujeitos sem o traço de animacidade, não qualificado para receber o papel temático de agente:

42. ? Rafael assaltou no centro da cidade.

43. Rafael foi assaltado no centro da cidade.

Outras duas restrições se aplicam à ocorrência da construção. A primeira diz respeito à categoria semântica do verbo: o objeto precisa ser [+afetado], o que limita a construção à classe dos verbos "quasi-instrumentais" - verbos que "tomam um objeto direto que pressupõe a manipulação de um instrumento, mesmo que implicitamente" (CYRINO, 2007, p.89). A segunda restrição estabelece que as sentenças devem ser atélicas:

44. *A revista xerocou ontem à noite.

Finalmente, a promoção do argumento se distingue tanto das construções incoativas, por não aceitarem verbos inacusativos, quando das construções médias, por não exigirem advérbio especial e não necessariamente apresentarem um caráter genérico.

\section{Análise de corpora de fala}

Este estudo observou a produção da construção passiva pelos falantes do $\mathrm{PB}$ e do inglês através de uma análise de corpora de fala: O C-Oral-Brasil I (Raso \& 
Mello, 2012) e o Santa Barbara Corpus of Spoken American English (Du Bois et al., 2000-2005), respectivamente.

\subsection{Corpora}

\section{Santa Barbara Corpus of Spoken American English}

O Santa Barbara Corpus of Spoken American English ${ }^{8}$ (parte do projeto International Corpus of English) é um corpus oral compilado entre os anos 2000 e 2005 pelo Departamento de Linguística da Universidade da Califórnia, em Santa Bárbara, sob a direção de John W. Du Bois. ${ }^{9}$ As primeiras quatro partes do corpus, disponíveis tanto em forma de arquivos de texto quanto de áudio na página do departamento, apresentam um total de 249 mil palavras e trazem transcrições de 60 interações conversacionais de falantes de várias localidades dos Estados Unidos.

Os arquivos do SBCSAE trazem etiquetas de prosódia, mas não de categorias gramaticais. As transcrições foram então etiquetadas por categorias gramaticais através da versão gratuita do etiquetador online $\mathrm{CLAWS}^{10}$. As buscas e análises primárias foram realizadas através do concordanceador de textos $\mathrm{AntConc}^{11}$.

\section{C-Oral-Brasil I}

O C-Oral-Brasil ${ }^{12}$ é um projeto da Faculdade de Letras da Universidade Federal de Minas Gerais, organizado e coordenado por Raso e Mello, e se espelha no projeto de compilação de corpora oral das línguas românicas C-Oral-Rom. O C-Oral-Brasil é dividido em uma parte formal, ainda em fase de coleta, e uma parte informal, que compõe o C-Oral-Brasil I (utilizado neste estudo). A parte informal do corpus é composta por 263 mil palavras, e está igualmente dividida em três domínios: monólogos, diálogos e conversações. Ao contrário do SBCSAE, o C-Oral-Brasil I é etiquetado de acordo com categorias gramaticais.

8 Doravante SBCSAE.

9 As informações sobre o Santa Barbara Corpus of Spoken American English foram obtidas na página do projeto: < http://www.linguistics.ucsb.edu/research/santa-barbara-corpus $>$. Acessado em $15 / 04 / 2015$.

10 Disponível em <http://ucrel.lancs.ac.uk/claws/>. Acessado em 15/04/2015.

11 Disponível em <http://www.laurenceanthony.net/software.html > . Acessado em 15/05/2015.

12 As informações sobre o C-Oral-Brasil foram obtidas na página do projeto: <http://c-oral-brasil. org/>. Acessado em 15/04/2015. 
Neste estudo, o corpus foi acessado através da Linguateca ${ }^{13}$, página dedicada à oferta de recursos para o processamento computacional da língua portuguesa onde é possível acessar um grande número de outros corpora do português. Santos (2014) disponibiliza uma lista de códigos para a contagem de construções passivas e de verbos principais para o cálculo da frequência relativa ${ }^{14}$.

\subsection{Dados}

\section{Santa Barbara Corpus of Spoken American English}

Foram encontradas 323 ocorrências de construções passivas no SBCSAE. Na tabela 1, estão listados os dez verbos mais frequentes dentre as ocorrências da construção passiva, o número total de ocorrências do lema no corpus e o valor da frequência relativa da construção passiva:

TABELA 1: verbos do inglês mais frequentes nas ocorrências de construções passivas no SBCSAE

\begin{tabular}{llll} 
Verbo & $\begin{array}{l}\text { Frequência } \\
\text { (passiva) }\end{array}$ & $\begin{array}{l}\text { Frequência } \\
\text { (lema) }\end{array}$ & $\begin{array}{l}\text { Frequência } \\
\text { relativa }\end{array}$ \\
\hline 1. call & 19 & 188 & 0,1011 \\
2. build & 12 & 50 & 0,2400 \\
3. make & 12 & 317 & 0,0379 \\
4. give & 7 & 184 & 0,0380 \\
5. put & 7 & 343 & 0,0204 \\
6. enter & 6 & 8 & 0,7500 \\
7. seat & 6 & 13 & 0,4615 \\
8. retire & 5 & 16 & 0,3125 \\
9. bring & 4 & 89 & 0,0449 \\
10. use & 4 & 180 & 0,0222
\end{tabular}

O verbo use, que ocupa o décimo lugar da tabela de frequências, foi escolhido dentre outros dois verbos também com 4 ocorrências no corpus: o expose e o lead. $\mathrm{O}$ verbo expose ocorreu 4 vezes na construção passiva e 3 na construção ativa no corpus, apresentando uma frequência relativa discrepante de $57 \%$ em

13 Disponível em <http://www.linguateca.pt/>. Acessado em 15/04/2015.

14 Agradeço a Diana Santos (Universidade de Oslo e Linguateca) pela orientação na consulta ao corpus. 
relação aos outros verbos da lista. Sob a suspeita de que a configuração sintática verbo de ligação seguido da forma participial de expose componha uma única unidade representacional na língua inglesa, a busca feita no SBCSAE foi replicada no Corpus of Contemporary American English (COCA), corpus escrito com 450 milhões de palavras. Foi observado que o verbo expose ocorreu na construção passiva em pouco mais de $22 \%$ das ocorrências totais do lema. Para fins de comparação, as frequências relativas de todos os 12 verbos mais frequentes (os 9 mais frequentes e os 3 candidatos à décima posição) foi calculada no COCA, e estão listadas na tabela 2 :

TABELA 2: Frequências relativas dos verbos no SBCSAE e no COCA

\begin{tabular}{lll} 
Verbo & $\begin{array}{l}\text { Freq relativa } \\
\text { SBCSAE }\end{array}$ & $\begin{array}{l}\text { Freq relativa } \\
\text { COCA }\end{array}$ \\
\hline 1. call & 0,1011 & 0,0809 \\
2. build & 0,2400 & 0,1146 \\
3. make & 0,0379 & 0,0569 \\
4. give & 0,0380 & 0,0621 \\
5. put & 0,0204 & 0,0551 \\
6. enter & 0,7500 & 0,022 \\
7. seat & 0,4615 & 0,0413 \\
8. retire & 0,3125 & 0,0609 \\
9. bring & 0,0449 & 0,0558 \\
10. use & 0,0222 & 0,1017 \\
10a. expose & 0,5714 & 0,2253 \\
10b. lead & 0,2000 & 0,0257
\end{tabular}

A descrição ou até mesmo a discussão da natureza da alta ocorrência do verbo expose na construção passiva em comparação aos outros verbos da lista não entra no escopo deste estudo. A sua exclusão foi uma medida de cautela, de modo a evitar que haja influência de fatores desconhecidos nas análises aqui propostas.

$\mathrm{O}$ verbo lead, ainda que não apresente frequências relativas alarmantes, foi descartado por ter ocorrido no SBCSAE apenas em uma conversa sobre jogos de cartas. Neste caso, lead tem o sentido de mandar a primeira carta de um naipe, como ilustrado na sentença (45):

45. Can you play a club if spades were led $[\ldots]$ ? 
Posso jogar uma carta de paus se uma carta de espadas tiver sido jogada primeiro $[\ldots]$ ?

O verbo use foi então o mais apropriado para ser incluído na lista de verbos deste estudo pelo fato de sua ocorrência nos dois corpora não sugerir algum efeito de coocorrência, como expose, e de não ser sensível ao domínio conversacional, comolead.

Uma última observação deve ser feita a respeito da lista final de verbos. O verbo enter, que ocupa a sexta posição na tabela de frequências, é o único cuja ocorrência na construção passiva foi maior do que na construção ativa no SBCSAE. A decisão por mantê-lo na lista, apesar de sua frequência relativa discrepante (mais do que dois desvios padrões maior do que a média ${ }^{15}$ ), foi baseada na comparação com a frequência relativa observada no COCA. Como indicado na tabela 2, a proporção de ocorrências na construção passiva em relação à ativa vai de $75 \%$ no corpus oral para aproximadamente $2 \%$ no corpus escrito. Essa diferença abranda as suspeitas de que haja alguma motivação desconhecida para a coocorrência do verbo de ligação com a forma participial do verbo, ao contrário do que foi percebido para o verbo expose.

Foram encontradas 19.693 construções não passivas no SBCSAE, contra 323 construções passivas, como reportado acima. Ao todo, as passivas representam $1,6 \%$ das construções encontradas no corpus.

\section{C-Oral-Brasil I}

Foram encontradas 211 ocorrências da construção passiva no C-Oral-Brasil I, utilizando os mesmos critérios de busca descritos na seção 3.1.1. A tabela 3 mostra os dez verbos mais frequentes dentre as ocorrências da construção passiva, o número total de ocorrências do lema no corpus e o valor da frequência relativa da construção passiva:

15 Desvio padrão: 0,2439; média: 0,2029. 
TABELA 3 - Verbos do PB mais frequentes nas ocorrências de construções passivas no C-Oral-Brasil I

\begin{tabular}{llll} 
Verbo & $\begin{array}{l}\text { Frequência } \\
\text { (passiva) }\end{array}$ & $\begin{array}{l}\text { Frequência } \\
\text { (lema) }\end{array}$ & $\begin{array}{l}\text { Frequência } \\
\text { relativa }\end{array}$ \\
\hline 1. fazer & 25 & 1547 & 0,01616 \\
2. usar & 7 & 167 & 0,04192 \\
3. prender & 7 & 17 & 0,41176 \\
4. construir & 5 & 23 & 0,21739 \\
5. gerar & 5 & 7 & 0,71429 \\
6. promover & 5 & 5 & 1,0 \\
7. considerar & 4 & 10 & 0,4 \\
8. produzir & 4 & 17 & 0,23529 \\
9. colocar & 3 & 229 & 0,01310 \\
10. gravar & 3 & 55 & 0,05455
\end{tabular}

Foram encontrados 8 verbos com 3 ocorrências na construção passiva: aprovar, assaltar, colocar, destacar, dividir, gravar, jogar e obrigar. Os critérios que levaram à escolha dos itens colocar e gravar foram a frequência total do lema no corpus e a relação entre o número de passivas e não passivas. Na tabela 4 , podemos observar que o os verbos colocar e gravar possuem os maiores números de frequência total e os menores números de frequência relativa. Esta configuração está em conformidade com os objetivos do estudo, que procura observar a produção de construções passivas como alternativa à construção ativa, e não como expressão fixa.

TABELA 4: verbos com 3 ocorrências na construção passiva no C-Oral-Brasil I

\begin{tabular}{llll} 
Verbo & $\begin{array}{l}\text { Frequência } \\
\text { (passiva) }\end{array}$ & $\begin{array}{l}\text { Frequência } \\
\text { (lema) }\end{array}$ & $\begin{array}{l}\text { Frequência } \\
\text { relativa }\end{array}$ \\
\hline aprovar & 3 & 4 & 0,75 \\
assaltar & 3 & 3 & 1 \\
colocar & 3 & 229 & 0,0131 \\
destavar & 3 & 7 & 0,4286 \\
dividir & 3 & 27 & 0,1111 \\
gravar & 3 & 55 & 0,0545 \\
obrigar & 3 & 5 & 0,6
\end{tabular}


Estes critérios de seleção foram utilizados apenas para os verbos que apresentaram o mesmo número de ocorrências, e não para a lista como um todo. Seria certamente mais conveniente que dentre os dez verbos mais frequentes nas ocorrências de construções passivas no corpus não figurassem itens como o verbo promover, que ocorreu exclusivamente na construção passiva, ou ainda os verbos prender e gerar, que fogem da tendência geral de ocorrer muito menos frequentemente na construção passiva do que na construção ativa. A eliminação arbitrária destes verbos tão frequentes seria uma irresponsabilidade metodológica e colocaria uma barreira indesejável entre o estudo e a realidade da língua como mostrada no corpus.

Foram encontradas 25.977 construções não passivas no C-Oral-Brasil I, contra 211 ocorrências da construção passiva, como reportado acima. Ao todo, as passivas representam $0,8 \%$ das construções encontradas no corpus.

\subsection{Análise}

A tabela 5 traz um resumo das ocorrências da construção passiva nos dois corpora:

TABELA 5: Ocorrências de construções passivas e não passivas nos corpora de língua falada

\begin{tabular}{llll} 
Língua & Passiva & Não-Passiva & $\begin{array}{l}\text { Total de } \\
\text { construções }\end{array}$ \\
\hline PB & 211 & 25977 & 26188 \\
inglês & 323 & 19693 & 20016 \\
Total & 534 & 45670 & 46204
\end{tabular}

O número de ocorrências da construção passiva no corpus do inglês é relativamente duas vezes maior do que no corpus do PB. Estes números estão em concordância com os resultados obtidos por Duarte (1990), cuja análise de corpora de língua escrita do PB e do inglês mostram que, para cada construção passiva no inglês, havia 7 construções ativas, enquanto a relação no PB foi de uma construção passiva para cada 20 construções ativas. A autora mostrou ainda que, em números absolutos, a passiva ocorreu nos textos do inglês "mais do que o dobro de vezes do que nos textos do português" (p. 153). Uma comparação final do número de ocorrências da construção passiva no PB e no inglês revelou uma 
diferença significativa da frequência da construção nas duas línguas $\left(\chi^{2}=64,834\right.$, $\mathrm{GL}=1, p<.000)$.

\section{Discussão}

Como descrito na seção 1, a construção passiva apresenta forma de superfície idêntica no PB e no inglês. Seguindo a notação de Goldberg (1995), caracterizamos a construção passiva como na figura 2 :

FIGURA 2: Forma de superfície da construção passiva

\begin{tabular}{|lcccc|}
\hline Semântica: & ACT/DO & $($ pac & (agt) \\
& loc. verbal & ( & & $\mid$ \\
Sintaxe: & & & Sujeito & Adjunto \\
\hline
\end{tabular}

A primeira linha indica a semântica da construção passiva, onde se encontram os papéis de seus argumentos: o "paciente"16, em posição de tópico, e o "agente", ocorrendo opcionalmente. Na segunda linha estão mapeados o SV composto pelo verbo de ligação e o verbo principal no particípio, o sujeito e o adjunto preposicional encabeçado pela preposição por (ou by, no inglês).

A confirmação da discrepância distribucional oferecida pela análise dos corpora é informativa principalmente por se tratar de produção oral, que reflete mais fielmente o estado da língua do que a produção escrita. A fala representa uma interação face-a-face, tem planejamento simultâneo (ou quase simultâneo), não tem possibilidade de apagamento ou consulta, e apresenta ampla possibilidade de reformulação a partir do retorno imediato do ouvinte (MAC-KAY, 2000). Ainda, fatores extralinguísticos como classe social e escolaridade segmentam a fala em dimensão menor do que a escrita - os desvios em relação à norma padrão ou o uso de variantes inovadoras ocorrem em todas as classes, não obstante as diferenças na frequência. Assume-se, então, que o falante utilize as construções

16 Sendo os papéis dos argumentos derivados da construção, e não de uma lista determinada a priori (GOLDBERG, 2006), o papel de paciente é aqui utilizado para indicar tanto argumentos que sofrem mudança de estado, mudança de lugar (tema) ou argumentos não afetados. 
mais prontamente disponíveis para a expressão de uma mensagem ${ }^{17} \mathrm{e}$, no caso do $\mathrm{PB}$, a passiva não parece ser uma delas.

A diferença distribucional atestada na análise de corpus mostra ainda que a congruência na forma de superfície ilustrada na figura 2 não é suficiente para reduzir as construções uma à outra nas duas línguas. Enquanto o inglês apresenta uma variedade pragmática maior para a construção passiva do que o $\mathrm{PB}$, as alternativas para topicalização do objeto e apagamento ou adjunção do agente proposicional presentes nesta língua parecem estar causando o preterimento da construção passiva ${ }^{18}$. É possível conjecturar, então, que existam restrições pragmáticas à ocorrência da passiva no $\mathrm{PB}$, que são ausentes no inglês e resultam na discrepância distribucional observada.

Este estudo não tem por objetivo explicitar a motivação para a aparente rejeição da construção passiva no $\mathrm{PB}$, embora este seja um ponto de interesse para análises futuras. Cyrino (2007) argumenta que o surgimento das construções com promoção do objeto não elimina a necessidade da construção passiva no PB pelo fato de serem restritas à classe dos verbos quasi-instrumentais ocorrendo em sentenças atélicas com SN [-animado], restrição que não se aplica à construção passiva:

46. *O livro está comprando.

47. O livro está sendo comprado.

A diferença essencial entre as duas opções é a de que (45) é inerentemente não agentiva, enquanto (46) permite a projeção de um agente. Sob o ponto de vista desta autora, as construções com partícula se, com promoção do objeto e as passivas servem a propósitos relacionados, mas distintos: a primeira indetermina o sujeito; a segunda, como indica o próprio nome, promove o objeto a tópico, enquanto a terceira suprime o agente da proposição. Esses três efeitos semânticopragmáticos são obtidos no inglês através da construção passiva - com exceção apenas da indeterminação do sujeito, que pode ser indicada também pelo uso do pronome pessoal they.

Finalmente, argumentamos que a visão não transformacional da construção passiva de fato esgota as possibilidades desta construção, especialmente nos casos do inglês em que a passiva é licenciada a despeito da ausência do objeto.

17 Neste estudo, entendemos por mensagem a estrutura conceitual a ser formulada.

18 Ainda que a discrepância distribucional das construções corrobore estas suspeitas, este estudo por si não é suficiente para que seja estabelecida uma relação causal entre a opcionalidade do PB e o preterimento da passiva. São necessários estudos qualitativos de corpora. 
Só é possível realizar uma análise translinguística como feita neste estudo se a passiva for considerada uma construção dentro da Gramática de Construções (cf. GOLDBERG, 1995), uma vez que seu sentido parece não estar limitado àquele de sua dita contrapartida ativa. De maneira análoga à qual foram comparadas as estruturas sintáticas resultativas adjetivas e causativas com verbos de modo de movimento do inglês às suas estruturas correspondentes no $\mathrm{PB}$, contrastamos os níveis de produtividade da construção nestas duas línguas - diferença que se mostrou significativa não obstante a congruência na estrutura sintática e nos efeitos semântico-pragmáticos. A verificação da diferença distribucional serviu de base para oferecermos a hipótese de que a construção passiva recupera representações construcionais distintas em PB e em inglês. É necessário, ainda, examinar os contextos pragmáticos que restringem sua ocorrência em cada uma das línguas, como forma de descrever a construção passiva com precisão maior daquela da qual dispomos atualmente. Outros desdobramentos possíveis dizem respeito a estudos que se baseiem na comparação entre o inglês e o PB, como estudos de tradução e bilinguismo, que devem atentar à diferença translinguística da construção para que não rendam resultados equívocos.

\title{
Divergences between the passive construction in Brazi- lian Portuguese and English: evidence from oral corpus
}

\begin{abstract}
A transformational view of the passive construction does not account for all its possibilities. In this study, we propose a constructional view of the passive, in which it is considered an independent theoretical entity. Although the passive is syntactically identical in Brazilian Portuguese (BP) and English, this construction cannot be considered equivalent in both languages due to the presence of alternatives in BP to reach the semanticpragmatic effects that are only reached in English through the passive. Considering the passive as a construction in the Construction Grammar (GOLDBERG, 1995; 2006), we carried out an analysis of spoken corpora in both BP and English, in which we were able to attest a distributional difference of the passive between these two languages irrespective of its syntactic and functional congruity. We argue that the discrepancy observed in the construction frequency stems from the fact that passive retrieves different constructional representations in BP and English.
\end{abstract}

Keywords: Passive Construction; Construction Grammar; Corpus Analysis 
Referências

CHIERCHIA, G. A semantics for unaccusative and its syntactic consequences. In: ALEXIADOU, A.; ANAGNOSTOPOULOS, E.; EVERAERT, M. (orgs.). The Unaccusativity Puzzle - Explorations of the Lexicon-Syntax Interface. Oxford/New York: Oxford University Press, 2004.

CAMBRUSSI, M. F. Alternância Causativa de Verbos Inergativos no Português Brasileiro. Tese de Doutorado - Universidade Federal de Santa Catarina, Florianópolis, 2009.

CYRINO, S. M. L. Construções com se e promoção de argumento no português brasileiro - uma investigação diacrônica. Revista da ABRALIN, v. 6, n.2, p. 85116, 2007.

DAVISON, A. Peculiar passives. Language, v. 56, n. 1, p. 42-66, 1980.

DUARTE, Y. As passivas no português e no inglês: uma análise funcional. D.E.L.T.A., n. 6, v.2, p. 139-167, 1990.

DU BOIS, J. W.; CHAFE, W. L.; MEYER, C.; THOMPSON, S. A.; Englebretson, R.; Martey, N. Santa Barbara corpus of spoken American English, Parts 1-4. Philadelphia: Linguistic Data Consortium, 2000-2005.

ELLIS, N. C. Constructions, Chunking and Connectionism: The Emergence of Second Language Structure. In: DOWTY, C. J.; LONG, M. H. (Ed.). The Handbook of Second Language Acquisition. Malden, MA: Blackwell, p. 63103, 2003.

GABRIEL, R. Mecanismos cognitivos envolvidos na aquisição e processamento de construções passivas. Caderno de Estudos Linguísticos, Campinas, n.45, p. 89-98, 2003.

GIVON, T. Syntax: A Functional-Typological Introduction, vol. II. Amsterdam: John Benjamins, 1990.

GOLDBERG, A. Constructions: A Construction Grammar Approach to Argument Structure. Chicago: University of Chicago Press, 1995.

GOLDBERG, A. Constructions at Work - The Nature of Generalizations in Language. Oxford/New York: Oxford University Press, 2006.

HAEGEMAN, L.; GUÉRON, J. English Grammar - A Generative Perspective. Malden, MA.: Blackwell, 1999. 
HAWAD, H. F. A Voz Verbal e o Fluxo Informacional do Texto. D.E.L.T.A., n. 20, v.1, p. 97-121, 2004.

JUFFS, A. An overview of the second language acquisition of the links between verb semantics and morpho-syntax. In: ARCHIBALD, J. (Ed.). Second Language Acquisition and Linguistic Theory. Oxford: Blackwells, p. 187-227, 2000.

LEVIN, Beth. English Verb Classes and Alternations: A Preliminary Investigation. Chicago and London: The University of Chicago Press, 1993.

MAC-KAY, A.P.M.G. Atividade verbal: processo de diferença e integração entre fala e escrita. São Paulo: Plexus, 2000.

OLIVEIRA, C. S.; SOUZA, R. A. Uma exploração da aprendizibilidade da construção resultativa do inglês por bilíngues do par linguístico português do Brasil e inglês. Confluência - Revista do Instituto de Língua Portuguesa, n. 43, p. 252-260, 2012.

RASO, T.; MELLO, H. C-Oral-Brasil I. Belo Horizonte: Editora UFMG, 2012.

SAID ALI, M. O pronome "se". In: SAID ALI, M. Dificuldades da Língua Portuguesa $-7^{\mathbf{a}}$ ed. Rio de Janeiro: ABL, p. 101-119, 2008.

SANTOS, D. Podemos contar com as contas? In: ALUÍSIO, S.; TAGNIN, S. (eds.). New Language Technologies and Linguistic Research: A Two-way Road. Cambridge: Cambridge Scholars Publishing, p. 194-213, 2014.

SOUZA, R.; MELLO, H. Realização argumental na língua do aprendiz de línguas estrangeiras - possibilidades de exploração da interface entre semântica e sintaxe. Revista Virtual de Estudos da Linguagem - ReVEL, n. 5, 2007. ISSN 16788931 [www.revel.inf.br].

TSENG, J. English Prepositional Passive Constructions. In: MULLER, S. (Ed.). Proceedings of the 14th International Conference on Head-Driven Phrase Structure Grammar. Stanford Department of Linguistics and CSLI's LinGO Lab. Stanford, CA: CSLI Publications, p. 271-286, 2007.

VAN RIEMSDIJK, H.; WILLIAMS, E. Introduction to the Theory of Grammar. Cambridge, MA.: The MIT Press, 1986.

Submetido: 30/03/2016

Aceite: 06/09/2016 